\title{
Modeling and Application of Process Damping in Milling of Thin-Walled Workpiece Made of Titanium Alloy
}

\author{
Xin Li, ${ }^{1}$ Wei Zhao, ${ }^{1}$ Liang $\mathrm{Li}^{1}{ }^{1}$ Ning $\mathrm{He},{ }^{1}$ and ShengWei $\mathrm{Chi}^{2}$ \\ ${ }^{1}$ College of Mechanical \& Electrical Engineering, Nanjing University of Aeronautics and Astronautics, Nanjing 210016, China \\ ${ }^{2}$ Xian Institute of Applied Optics, Xian 710065, China \\ Correspondence should be addressed to Xin Li; tieqxin@163.com and Wei Zhao; nuaazw@nuaa.edu.cn
}

Received 20 August 2014; Revised 25 October 2014; Accepted 13 November 2014

Academic Editor: Didier Rémond

Copyright (c) $2015 \mathrm{Xin} \mathrm{Li} \mathrm{et} \mathrm{al.} \mathrm{This} \mathrm{is} \mathrm{an} \mathrm{open} \mathrm{access} \mathrm{article} \mathrm{distributed} \mathrm{under} \mathrm{the} \mathrm{Creative} \mathrm{Commons} \mathrm{Attribution} \mathrm{License,} \mathrm{which}$ permits unrestricted use, distribution, and reproduction in any medium, provided the original work is properly cited.

\begin{abstract}
The modeling as well as application of process damping in milling of thin-walled workpiece made of titanium alloy is investigated. Titanium alloy used commonly in aviation industry is one typical difficult-to-machine material. Chatter usually occurs in cutting of titanium alloy, which results in poor surface quality and damaged tool. Thus, chatter is one important restriction for the quality and efficiency of titanium alloy manufacture, especially for the thin-walled workpiece made of titanium alloy due to poor structural stiffness. Process damping results from interference between flank face and machined surface, which is critical but usually ignored in chatter analysis for difficult-to-machine material. The paper presents one nonlinear dynamic model considering process damping for milling of thin-walled workpiece made of titanium alloy and designs antivibration clearance angle to suppress chatter based on the model. The experimental and computational results indicate that the presented methods for chatter stability analysis are reasonable, and the antivibration clearance angle designed is effective in suppressing chatter and improving machining quality.
\end{abstract}

\section{Introduction}

Titanium alloy is used widely in aerospace industry, which possesses excellent overall performances owing to high specific strength, low density, strong heat, and corrosion resistance; corresponding thin-walled structural parts made of titanium alloy also play one essential role in aerospace industry. However, titanium alloy is also one typical type of difficult-to-cutting material, which possesses low machinability owing to poor thermal conductivity, high chemical activity, and the severe hardening. Particularly, due to large unit cutting force and low elastic modulus, chatter usually occurs in machining process. Vibration marks left on the machined surface are usually required to be removed manually, which result in low machining efficiency. Worse, it may result in scraped workpiece and destroyed tool. Chatter problem is one of the main restrictions to the machining quality and efficiency of titanium alloy, which is much more troublesome in milling of thin-walled workpiece made of titanium alloy due to the poor structural stiffness.

The methods to suppress chatter can all be attributed to increase the damping of system. Damping of cutting system includes structural damping of machine tool and process damping.

Process damping (PD) results from interference between flank face of tool and undulations left on the workpiece. Tlusty and Ismail [1] showed that process damping has a significant effect on chatter stability decreasing with cutting speed. Structural damping can be identified using modal analysis easily. However, the identification as well as modeling of process damping has proved to be very difficult, and currently there is no practical method for its measurement or estimation. Altintas and Weck have addressed the process damping as the most challenging unsolved problems [2]. Therefore, in most of the studies, the effect of process damping is ignored, leading to significant errors in estimation of the stability limit $[3,4]$.

In one of the early works, the regenerative chip thickness effect on process stability is modeled by Das and Tobias, where the contact between the tool flank face and the undulations left on the surface was not considered. In this work [5], a velocity term in addition to the structural damping is introduced into the system equations increasing process stability. 


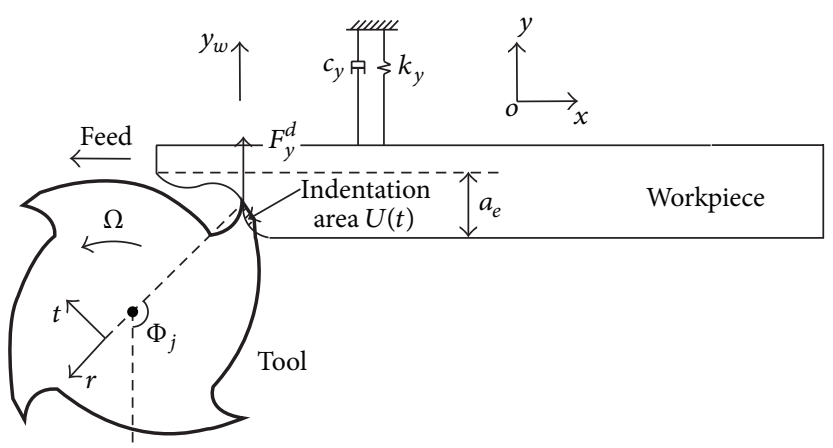

(a)

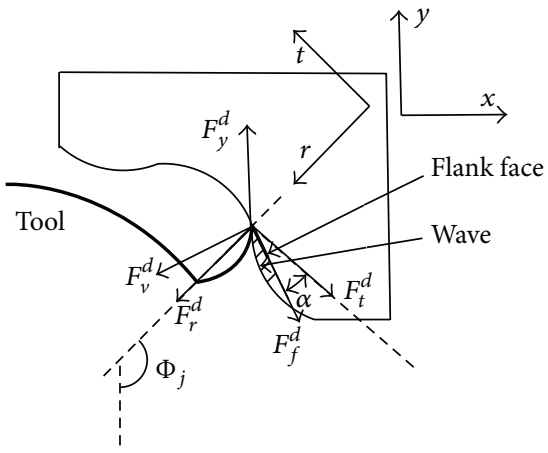

(b)

FIGURE 1: End milling system dynamics.

Later on, the focus of the research on dynamic cutting force coefficients shifted toward the identification and modeling of dynamic cutting force coefficients. The results of the CIRP efforts on dynamic cutting are summarized by Tlusty [6], where the difficulty of the measurements and the inconsistency of the test data from different labs are discussed. Sisson and Kegg [7], Wu [8], Lee et al. [9], and Shawky and Elbestawi [10] showed that the contact forces due to flank-wave interaction contribute to the dynamic of the cutting process by increasing the overall damping acting on the system. Altintas et al. [11] developed a dynamic force model which includes chip thickness, velocity, and acceleration terms. They identified dynamic cutting force coefficients from a series of dynamic cutting tests, where the cutting tool is oscillated by a fast tool servo at the desired frequency and amplitude.

Compared to turning, the reports on the process damping in milling, especially for the thin-walled workpiece, are much fewer, because milling is one discontinuity and time-invariant cutting process and the descriptions of process damping are much more complicated. For thin-walled workpiece, the modal parameters are also time-invariant, which increase the difficulties in stability analysis furthermore. Huang and Junz Wang $[12,13]$ extended analytical modeling of the milling process to include process damping effects. In their model, two cutting mechanisms (shearing and plowing) and two process damping effects (direction and magnitude) are included. The analytical nature of this model makes it possible to determine unknown process damping coefficients from measured vibration signal during milling. Budak and Tunc [14-17] considered the effect of process damping as an additional damper in the zero order MFS. They identified the additional damping coefficients by measuring stability limits experimentally and fitting the results to the stability model and studied the effects of tool geometry and cutting conditions on process damping. Ahmadi and Ismail [18, 19] simplified process damping to a piecewise linear viscous damper by assuming small amplitude of vibration and integrated the equivalent viscous model of process damping into the multifrequency solution and the semidiscrete method to establish the stability lobes in milling.

It can be known from above that higher stable cutting depth can be achieved under the effect of process damping, and high efficiency cutting can be achieved at low speeds. This can be important to increase machining productivity of titanium alloy, especially for the thin-walled workpiece with weak structural stiffness, because low cutting speeds have to be used for longer tool life due to low machinability. Besides, process damping has a lot to do with tool geometry; design of tool geometry is very important in suppressing chatter. However, very few cases have been reported for the application of process damping in designing of tool for milling of titanium alloy.

In this paper, one nonlinear milling dynamic model considering process damping for thin-walled workpiece made of titanium alloy is presented. In the model, indentation area arised from face-wave interference is calculated and stability limits are predicted by time domain simulations. Based on the model, antivibration clearance angle is designed to increase process damping and expand stable region further.

\section{Modeling of Process Damping}

2.1. Formation Mechanism of Process Damping. In finish machining, the stiffness of a thin-walled workpiece is far lower than that of the cutting tool. It is usually assumed that spindle tool is a rigid and the thin-walled workpiece can be considered to have a degree of freedom as shown in $y$ direction in Figure 1(a). The 1 DoF model shown in Figure 1(a) is widely used in the dynamic analysis for milling of thinwalled workpiece $[20,21] . \Phi_{j}$ is the angular position of the $j$ th cutting tool. $\Omega$ is the spindle speed. $y_{w}$ is the vibration displacements of workpiece determined in the normal $(y)$ direction, the wave on machined surface left behind in radial direction (i.e., chip thickness or radial direction), and $t$ direction represents the cutting speed direction. The interference between flank face and wave will occur when the chatter amplitude grows larger. The flank face of the tool indents into the wave, as shown in Figure 1. As a result, indentation forces (i.e., $F_{v}^{d}$ and $F_{f}^{d}$ ) arise in normal, $v$, and frictional, $f$, directions on the tool flank face as shown in Figure 1(b), which create a damping effects (i.e., process damping effects). The damping forces in $v$ and $f$ directions acting on each tooth are oriented and summed up as a resultant damping force in $y$ directions. 


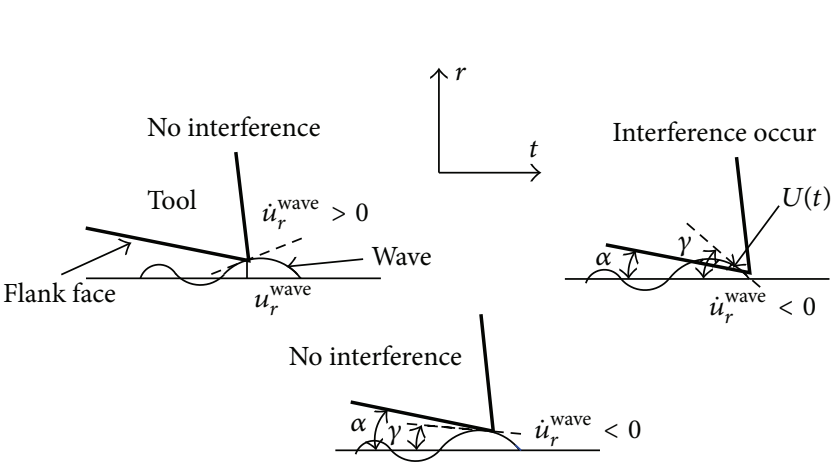

(a)

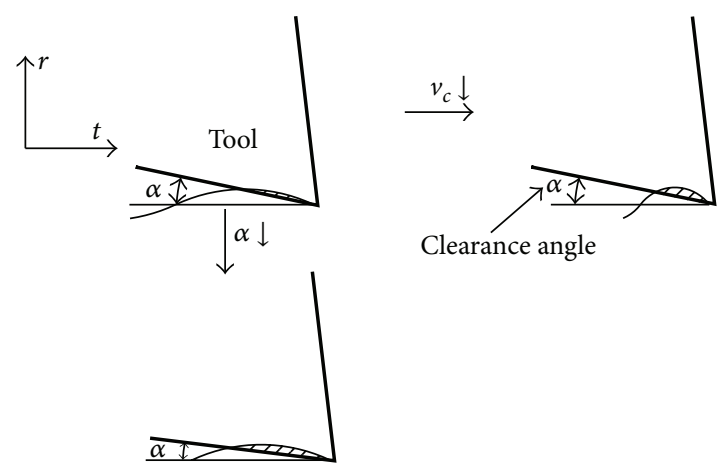

(b)

FIGURE 2: Formation mechanism of indentation area

Indentation forces (i.e., $F_{v}^{d}$ and $F_{f}^{d}$ ) are proportional to indentation area $U(t)$; the calculation method of $U(t)$ is presented in Section 2.2. In Figure 2(a), $\alpha$ is the clearance angle of tool, and angle $\gamma$ represents the slope of wave left in radial direction. $u_{r}^{\text {wave }}$ shown in Figure 2(a) is the radial coordinate values of wave, which represent the radial vibration displacement. The instantaneous slope of wave represents the radial vibration speed (i.e., $\dot{u}_{r}^{\text {wave }}$ ). It is assumed that the tool does not indent the previous wave as shown in Figure 2(a). Therefore, the interference between flank face and workpiece occurs only as the tool slides down the wave, where $\dot{u}_{r}^{\text {wave }}<0$. The occurrence of interference is determined by the relationship between $\alpha$ and $\gamma$. It can be seen from Figure 2(a) that the interference will occur when $\alpha<\gamma$. If $\dot{u}_{r}^{\text {wave }}$ satisfies the conditions of (1), the interference will occur:

$$
\begin{gathered}
\dot{u}_{r}^{\text {wave }}<0, \\
-\frac{d u_{r}^{\text {wave }}}{d s}=-\frac{d u_{r}^{\text {wave }}}{d t} \frac{d t}{d s}=-\frac{\dot{u}_{r}^{\text {wave }}}{v_{c}}=\tan (\gamma), \\
\tan (\alpha)<\tan (\gamma) .
\end{gathered}
$$

In (1) $v_{c}$ is the cutting speed, $s$ represents tangential arc length of tool edge, and $t$ is time here $\left(v_{c} t=s\right)$. It can be known from (1) that interference is easy to occur; as $v_{c}$ and $\alpha$ decrease, indentation area and process damping will also increase. The law is also shown in Figure 2(b).

2.2. Calculation of Indentation Area. The calculation of indentation area $U(t)$ shown in Figure 1(a) is rather complicated, which is also the basis of calculation of indentation force (as seen in (8)). As shown in Figure 3, the cutting tool is divided into a number of axial elements; elemental axial width is $d z$. In axial level $z$, point $A$ represents the current position of the tool edge, which can be also seen in Figure 4(a); correspondingly, $u_{r, 0}^{\text {wave }}$ is the current radial coordinate values of wave. As shown in Figure 4(a), $B_{i}(i=$ $1,2,3 \ldots)$ represent the point on the surface wave generated by the tool edge in the previous time step; corresponding radial coordinate value of wave calculated in previous time steps is $u_{r, i}^{\text {wave }}$. For every $B_{i}, C_{i}$ is the corresponding point

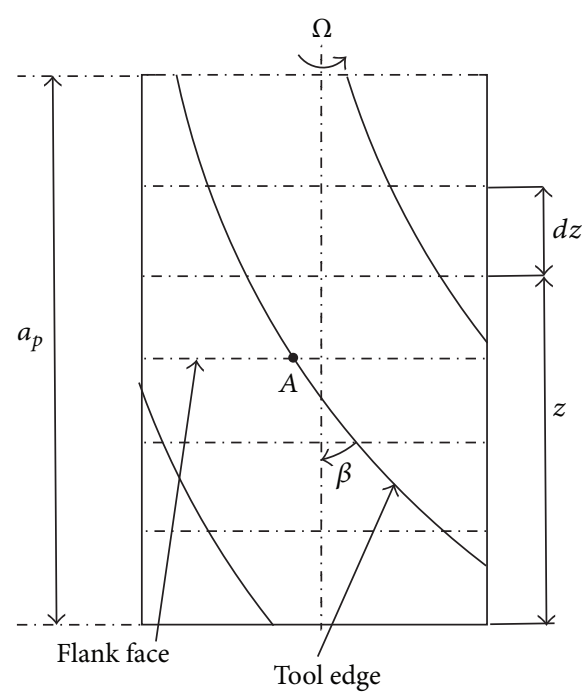

FIGURE 3: Digitized end mill model.

on the flank face; $u_{r, i}^{\text {flank }}$ is its radial coordinate values. The distance between $B_{i}$ and $C_{i}$ is $d_{i} . d_{0}$ is zero. The indentation area $U(t)$ in every axial level is bounded by the tool flank face and the workpiece surface wave. This area is calculated at each simulation time step numerically.

The calculation of $u_{r, i}^{\text {flank }}$ is calculated according to (2); here, $\Delta s=v_{c} \Delta t$ is the tangential arc length between adjacent two time points. $\Delta t$ is the simulation time step:

$$
\begin{gathered}
z_{i}=i \Delta s, \\
u_{r, i}^{\text {flank }}=u_{r, 0}^{\text {wave }}+z_{i} \tan (\alpha), \\
d_{i}=u_{r, i}^{\text {wave }}-u_{r, i}^{\text {flank }} .
\end{gathered}
$$

The intersection point of flank face and wave, $D$, needs to be searched in the calculation process. As shown in Figure 4(b), when $d_{i}<0$, the calculation of indentation area can stop. The index of $d_{i}$ front and back the intersection can be recorded as $n-1$ and $n$, respectively; here $d_{n-1}>0, d_{n}<0$; 


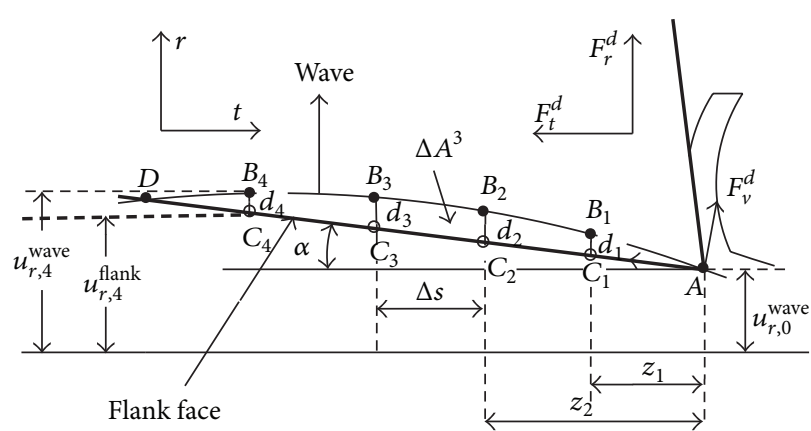

(a)

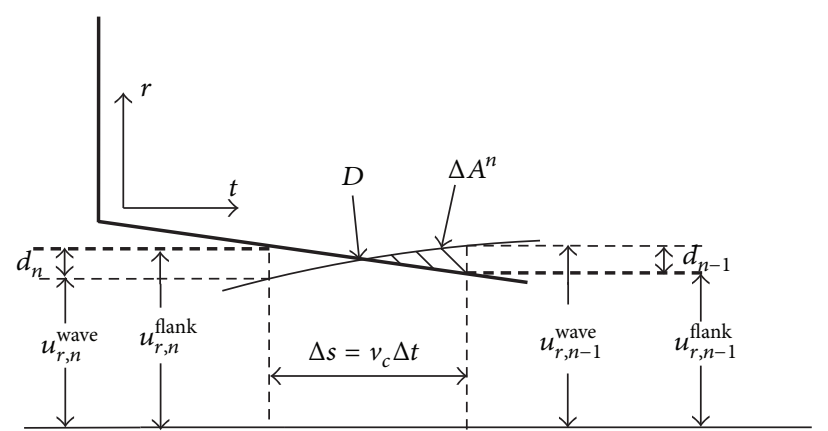

(b)

FIGURE 4: Calculation of indentation area.

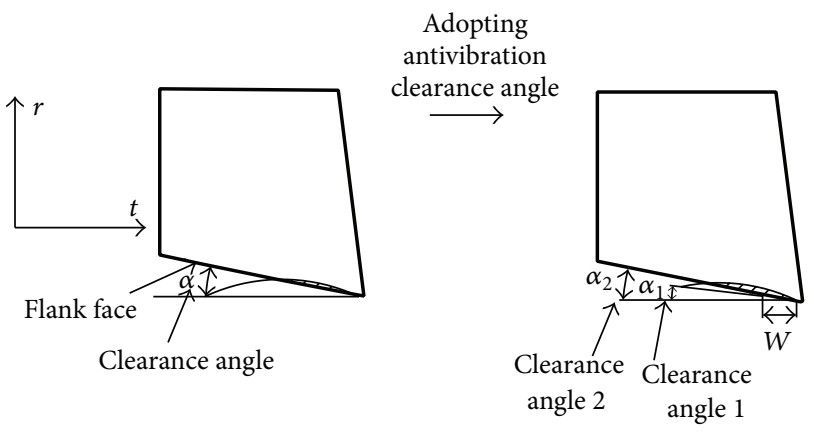

FigURE 5: Effects of antivibration clearance angle on indentation area.

thus, indentation area $U(t)$ can be calculated by summing up the discrete areas according to

$$
\begin{gathered}
\Delta A^{i}=\left(\frac{d_{i}+d_{i-1}}{2}\right) \Delta s, \\
\Delta A^{n}=\frac{\left(d_{n-1}\right)^{2}}{2\left(d_{n-1}-d_{n}\right)} \Delta s, \\
U(t)=\sum_{i=1}^{n} \Delta A^{i} .
\end{gathered}
$$

\subsection{Effects of Antivibration Clearance Angle on Process Damp-} ing. It can be seen from (1) that interference is much easier to occur as cutting speed and clearance angle decreases, therefore the lower speed and smaller clearance angle can increase the process damping. However, in the tool design, severe extrusion is easy to occur and the surface quality will become very poor if the clearance angle is too small. Therefore, transition edge needs to be adopted in design. As shown in Figure 5, the tools modified have two clearance angles, $\alpha_{1}$ and $\alpha_{2} ; \alpha_{1}$ is designed to be smaller to suppress vibration, which can be named antivibration angle; the length of its corresponding transition edge is $W$.

The calculation of indentation area follows the methods provided in Section 2.2; the main parameters in Figure 6 are the same as ones in Figure 4(a). Minor modification needs to be done because of the adoption of antivibration

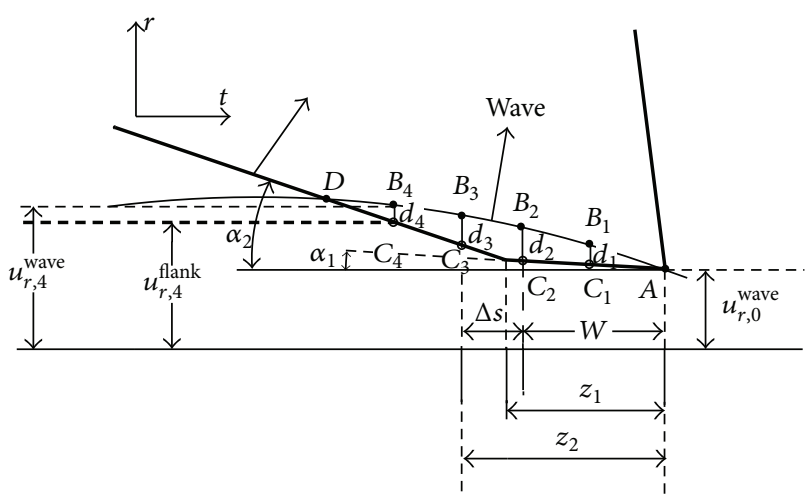

FIGURE 6: Calculation of indentation area (with antivibration clearance angle).

clearance angle. The calculation of $u_{r, i}^{\text {flank }}$ follows (4); then the calculation of indentation area also follows (3):

$$
\begin{gathered}
z_{i}=i \Delta s, \\
u_{r, i}^{\text {flank }}=u_{r, 0}^{\text {wave }}+z_{i} \tan \left(\alpha_{1}\right), \\
u_{r, i}^{\text {flank }}=u_{r, 0}^{\text {wave }}+W \tan \left(\alpha_{1}\right)+\left(z_{i}-W\right) \tan \left(\alpha_{2}\right), \\
d_{i}=u_{r, i}^{\text {wave }}-u_{r, i}^{\text {flank }} .
\end{gathered}
$$

\section{Time Domain Simulations}

3.1. Equations of Milling Dynamics. Dynamic cutting force model is of great importance in analysis of milling dynamics. At each axial level $z$, the location of the $j$ th cutting tooth is determined by its angular position $\Phi_{j}$ (as shown in Figure 1):

$$
\Phi_{j}(z)=\theta+(j-1) \frac{2 \pi}{N}-\frac{z \tan (\beta)}{R} \quad j=1: N .
$$

In (5), $N$ is the number of teeth, $\beta$ is the helix angle (as shown in Figure 3), and $R$ is the tool radius. $\theta$ is the angular position of tool bottom (axial level $z=0$ ), calculated from angular velocity $\Omega$ and the time $t: \theta=\Omega t$.

The dynamic cutting force is modeled using the linearedge force model [22], where elemental tangential and radial 
forces, $F_{t}$ and $F_{r}$, at flute, $j$, are expressed in terms of cutting force coefficients, $\left(K_{t c}, K_{r c}\right)$, edge force coefficients, $\left(K_{t e}, K_{r e}\right)$, instantaneous chip thickness, $h$, and elemental axial width, $d z$ (as shown in Figure 3):

$$
\begin{aligned}
& d F_{t, j}(t, z)=\left[K_{t c} h_{j}\left(\Phi_{j}(z)\right)+K_{t e}\right] d z, \\
& d F_{r, j}(t, z)=\left[K_{r c} h_{j}\left(\Phi_{j}(z)\right)+K_{r e}\right] d z .
\end{aligned}
$$

The differential cutting forces are then oriented in $y$ directions using the forces in $r$ and $t$ directions as follows:

$$
\begin{aligned}
d F_{y, j}(t, z)= & -d F_{t, j}(t, z) \sin \left(\Phi_{j}(z)\right) \\
& +d F_{r, j}(t, z) \cos \left(\Phi_{j}(z)\right) .
\end{aligned}
$$

For the $j$ th cutting flute, differential indentation forces acting on the axial level $z$, in normal $d F_{v}^{d}$ and in frictional $d F_{f}^{d}$ directions are given as

$$
\begin{aligned}
& d F_{v, j}^{d}(t, z)=K^{d} U_{j}(t, z) d z, \\
& d F_{f, j}^{d}(t, z)=\mu d F_{v, j}^{d}(t, z) .
\end{aligned}
$$

In $(8), U_{j}(t, z)$ is the indentation area at axial level $z$, which is calculated by methods provided in Sections 2.2 and 2.3. $\mu$ is the coefficient of contact friction between the flank face and the workpiece surface; $K^{d}$ is indentation coefficient. The process damping forces in $r$ and $t$ directions are expressed in terms of the forces in $v$ direction and the friction coefficient $\mu$ (as shown in Figure 1(b)):

$$
\begin{aligned}
& d F_{r, j}^{d}(t, z)=d F_{v, j}^{d}(t, z)(\cos (\alpha)+\mu \sin (\alpha)), \\
& d F_{t, j}^{d}(t, z)=d F_{v, j}^{d}(t, z)(-\sin (\alpha)+\mu \cos (\alpha)) .
\end{aligned}
$$

The differential process damping forces are then oriented in $y$ directions using the process damping forces in $r$ and $t$ directions as follows:

$$
\begin{aligned}
d F_{y, j}^{d}(t, z)= & -d F_{t, j}^{d}(t, z) \sin \left(\Phi_{j}(z)\right) \\
& +d F_{r, j}^{d}(t, z) \cos \left(\Phi_{j}(z)\right) .
\end{aligned}
$$

Thus, the equations of milling dynamic can be generated; it should be mentioned that the direction of cutting force exerted on the workpiece is opposite to the forces exerted on the tool:

$$
\begin{aligned}
& m_{y} \ddot{y}_{w}+c_{y} \dot{y}_{w}+k_{y} y_{w} \\
& =-g\left(\Phi_{j}(z)\right) \sum_{j=1}^{N} \sum_{k=1}^{S} \varphi_{r}(z)\left(d F_{y, j}+d F_{y, j}^{d}\right) d z
\end{aligned}
$$

where $S$ is the numbers of axial elements $\left(S d z=a_{p} ; a_{p}\right.$ is axial cutting depth), milling at small radial immersion is adopted in the paper, and, generally, only one tooth is cutting workpiece in one tooth passing period. $m_{y}, k_{y}$ are the modal mass, modal stiffness of workpiece, respectively (as shown in Figure $1(\mathrm{a}))$, and $\varphi_{r}(z)$ is the coefficient of vibration mode, which is set to 1 at the tool bottom $(z=0) . m_{y}, k_{y}$, and $\varphi_{r}(z)$ can be all obtained from FEM analysis. $\xi_{y}$ is the corresponding modal damping ratio, which can be obtained from modal test; then the modal damping can be also generated. $g$ is a unit step function which determines whether the tooth is in or out of the cutting, which will be discussed in Appendix. Besides, the calculation of dynamic chip thickness $h$ in (6) and $u_{r, i}^{\text {wave }}$ in (2) are rather complicated, which will be also discussed in detail in Appendix.

3.2. Determining Chatter Stability Lobes from Time Domain Simulations. Equation (11) is solved using the classical 4 th order Runge-Kutta method, where time increment $\Delta t$ is adopted as $10^{-5}$ seconds. Using the following steps, the stability limits are evaluated by finding the limiting axial cutting depth through a range of spindle speeds.

(1) Modal parameters of workpiece, cutting tool geometry, feed rate, tool orientation, entry angle and exit angle, cutting force coefficients, and a starting axial cutting depth, $a$, are specified.

(2) A range of spindle speeds and a spindle speed step size are specified.

(3) For a given spindle speed, a static time domain simulation is run (suppressing any tool and workpiece vibrations) and the maximum static uncut chip thickness, $h_{s, \max }$, is stored.

(4) A second time domain simulation is run. For given spindle speed and cutting depth, (11) is solved, the vibration displacements and dynamic chip thickness $h$ can be obtained during the process. The largest dynamic chip thickness of all cutting points on the tool, $h_{d, \max }$, is stored for the last few revolutions of the simulation.

(5) The nondimensional chatter parameter, $\eta$, is evaluated as

$$
\eta=\frac{h_{d, \text { max }}}{h_{s, \text { max }}} .
$$

(6) If $\eta$ is greater than a predetermined limit (1.25 is used in this paper), the process is unstable; otherwise the process is stable. The criterion to judge is provided in [23].

(7) If the process is stable, $a_{\min }$ is set to the current value of $a, a$ is doubled, and steps 3-6 are repeated until chatter occurs. Then $a_{\max }$ is set to the value of $a$ when chatter occurred.

If the process is unstable, $a_{\max }$ is set to the current value of $a, a$ is halved, and steps 3-6 are repeated until the process is stable. Then $a_{\min }$ is set to the stable axial cutting depth, $a$.

(8) Once the range $a_{\min }$ to $a_{\max }$ is found between which the limiting axial cutting depth lies, a bisection search is performed with $a_{\min }<a<a_{\max }$, repeating steps 3-6 until the limiting axial cutting depth, $a_{\text {lim }}$, is found within a given tolerance. 


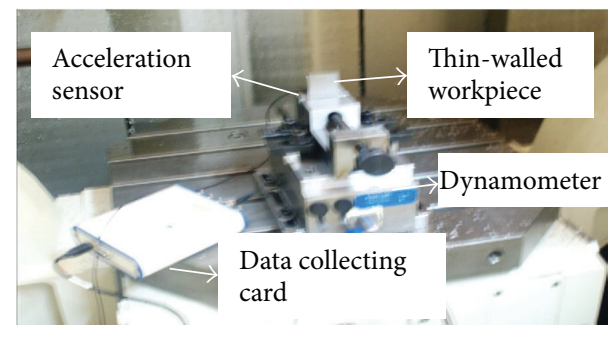

FIGURE 7: The milling experiments scenes.

\section{Comparison of Computational and Experimental Results}

To verify the nonlinear model provided in Sections $1-3$, the computations and experiments are all achieved. Computations are achieved in MATLAB according to time domain simulation provided in Section 3. Test scenes are shown in Figure 7, experimental equipments are as follows.

\section{Machine. Mikron UCP DURO710.}

Tool 1. Carbide end mill, $80 \mathrm{~mm}$ overall length, $40 \mathrm{~mm}$ overhang length, $20 \mathrm{~mm}$ edge length, $16 \mathrm{~mm}$ diameter, 4 flutes, $35^{\circ}$ helix angle, and $9^{\circ}$ clearance angle.

Tool 2 (with Antivibration Clearance Angle). Clearance angle: $\alpha_{1}$ is $4^{\circ} ; \alpha_{2}$ is $9^{\circ}$, length of transition edge: $W=60 \mu \mathrm{m}$, and the other parameters are the same as tool 1.

Workpiece Rectangular Thin-Walled Workpiece Made of Typical Titanium Alloy (Ti6AL4V), with Physical Properties. Young's modulus of elasticity $E=100 \mathrm{Gpa}$, density $\rho=$ $4400 \mathrm{~kg} / \mathrm{m}^{3}$, and Poisson's ratio $\mu=0.3$. The dimension of workpiece is $70 \times 40 \times 5 \mathrm{~mm}, 5 \mathrm{~mm}$ wall thickness. The clamping height is $30 \mathrm{~mm}$; thus the workpiece model shown in Figure 8 can be seen as one cantilever plate, the dimension of which is $40 \times 40 \times 5(\mathrm{~mm})$.

The modal stiffness and mass are different with the change of tool position; particularly the axial position of tool bottom $(z=0)$ has great effects on modal stiffness; therefore, the base line shown in Figure 8 is adopted. Axial cutting depths $\left(a_{p}\right)$ in experimental conditions are all chosen based on the line. The radial position of tool also has effects on the modal parameters. Therefore, only one thin coat of materials (thickness is equal to radial cutting depth) is removed for every workpiece. At last, the modal parameters of thin-walled workpiece are time-varying along feed direction in cutting, but the effects on stability prediction are much lighter than the first two. The modal stiffness and mass are calculated based on the point $A$ in Figure 8.

FEM is used to obtain modal stiffness and mass. The modal parameters (the first bending mode of the cantilever plate is adopted) in (11) are:

natural frequency: $\omega_{n y}=2771 \mathrm{~Hz}$;

modal damping ratio: $\xi_{y}=0.03$;

modal stiffness: $k_{y}=4.35 \times 10^{6} \mathrm{~N} / \mathrm{m}$.
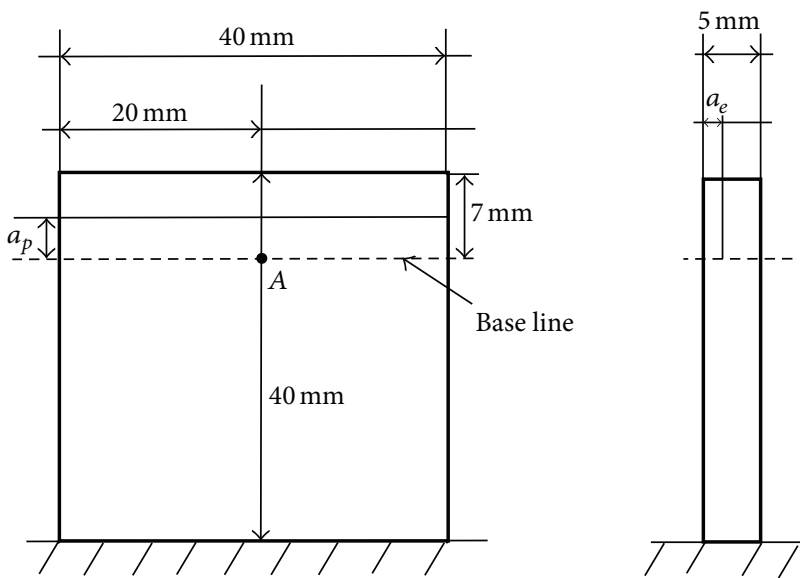

Figure 8: The workpiece model.
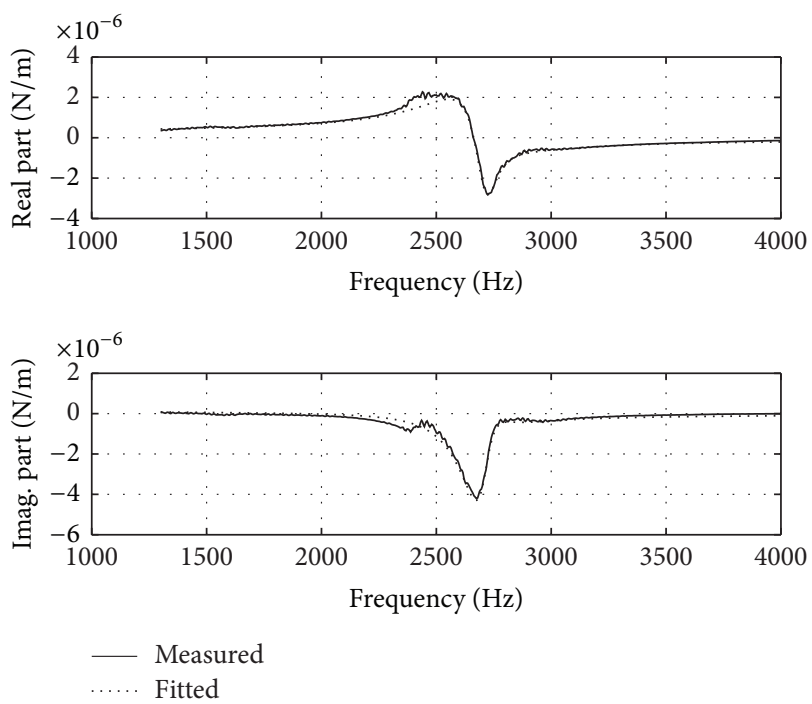

FIGURE 9: Frequency response function of workpiece.

The modal damping ratio $\xi_{y}$ is obtained from modal test. Figure 9 shows the measured frequency response function; modal parameters are identified by means of rational fraction method. The corresponding frequency response function fitted through these parameters is also shown in Figure 9. The $\omega_{n y}$ identified from modal test is $2680 \mathrm{~Hz}$, which is very close to the ones computed by FE model.

Cutting Force Coefficients. Tangential force coefficients $K_{t c}=$ $1800 \mathrm{Mpa}, K_{t e}=22 \mathrm{~N} / \mathrm{mm}$, and radial force coefficients $K_{r c}=$ $300 \mathrm{MPa}, K_{r e}=44 \mathrm{~N} / \mathrm{mm}$, which are reported in [22].

Process Damping Coefficients. Indentation coefficient $K^{d}$ and friction coefficient $\mu$, for titanium alloy Ti6AL4V, were reported at $30,000 \mathrm{~N} / \mathrm{mm}^{3}$ and 0.3 in [15]. To show the effects of process damping, the stability limits predicted without process damping are also generated.

Sensors. Piezoelectric acceleration sensors used to measure accerleration signals of workpiece; dynamometer used to 


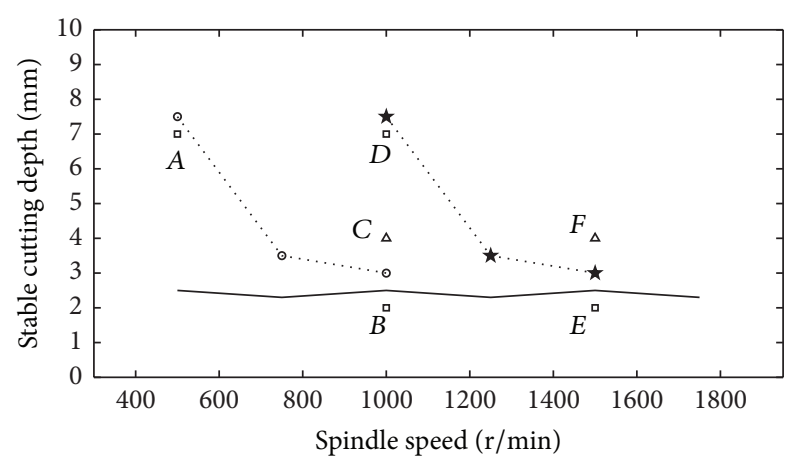

$\begin{array}{lll}\text { — Predicted without PD } & \Delta & \text { Experimental chatter } \\ \text {. } \text {.. Predicted with PD (tool 1) } & \square & \text { Experimental stable } \\ \text { } \star \text {. Predicted with PD (tool 2) } & & \end{array}$

FIGURE 10: Stability limits generated from computations and experiments.

measure cutting force. Acceleration sensor is attached to the corner point of workpiece.

\section{Data Acquisition Card. It is NIUSB9233.}

Main Parameters. Radial cutting depth $a_{e}=0.8 \mathrm{~mm}$, feed per tooth $f_{z}=0.06 \mathrm{~mm} / \mathrm{z}$, down milling, and mist cooling are considered.

The comparisons of stability limits generated by computation and experiments, respectively, are shown in Figure 10, from which it can be seen that the experimental results match with computational results well. The vibration signals measured in partial experimental conditions are shown in Figure 11. From Figure 11, it can be seen that vibration signals become divergent in unstable conditions, which is very steady in stable conditions.

The spectral analysis is also very important in chatter analysis. The corresponding spectral analysis results of vibration signals measured in partial experimental conditions are shown in Figure 12 (the sampling time is $0.5 \mathrm{~s}$ and the sampling region is near to the point $A$ in Figure 8 ). To see the spectrum clearly (spectral lines are very dense due to low rotating speed), the region from $1800 \mathrm{~Hz}$ to $2400 \mathrm{~Hz}$ is adopted to observe the milling stability in spectral analysis, the higher magnitude in frequency spectral concentrate on the region. From Figure 12, it can be seen that the main frequencies are all spindle rotating frequency (recorded as “ $\star$ ”) and tooth passing frequency (recorded as " $x$ ") in stable conditions, while the chatter frequency (recorded as "o") becomes prominent in unstable conditions. In unstable conditions (chatter), the phase $\beta=\omega_{c} T \in(\pi, 2 \pi)$ and chatter frequency do not coincide with spindle rotating frequency; the unstable types belong to Hopf bifurcation.

From Figures 10-12, it can be seen that the process damping increases the stability at low speed significantly and the method to predict stability limit is valid. For tool 1, the effect of process damping lasts until the spindle speed is up to $750 \mathrm{r} / \mathrm{min}$ (cutting speed $v_{c} \approx 38 \mathrm{~m} / \mathrm{min}$ ). For tool 2 , stable regions are expanded remarkably relative to tool 1 . The effects of process damping increase due to antivibration clearance angle, which lasts until the spindle speed exceeds $1200 \mathrm{r} / \mathrm{min}$ (cutting speed $v_{c} \approx 60 \mathrm{~m} / \mathrm{min}$ ).

Figure 13 shows the comparison of machined surface using two types of tool in the same condition $(1000 \mathrm{r} / \mathrm{min}$, $7 \mathrm{~mm}$ ). In Figure 13(a), a lot of inclined vibration marks are left on the machined surface when using tool 1, which is the symbol of the occurrence of regenerative chatter. Whereas in Figure 13(b) the surface is very smooth and only some straight marks are left (it indicates the slight imposed vibrations) when using tool 2 , antivibration clearance angles have significant effects on suppressing chatter.

Figure 14 shows the dynamic chip thickness, $h$, calculated in different working conditions adopted in experiments, which can indicate the criterion provided in Section 3 is valid.

The comparative analysis of computational and experimental results shows that the nonlinear model considering process damping can predict stability limits at low speed in milling of thin-walled workpiece made of typical titanium alloy accurately, including the working conditions using tool with antivibration clearance angle. For tool 1, process damping can expand the stable regions significantly; limits can be improved from $2.5 \mathrm{~mm}$ to over $7 \mathrm{~mm}$ at $500 \mathrm{r} / \mathrm{min}$ (cutting speed $v_{c} \approx 25 \mathrm{~m} / \mathrm{min}$ ). The tool 2 can increase the process damping further and expand the speed range of process damping effect; the laws presented by (1) are proved fully.

\section{Discussions and Conclusions}

Chatter problem in milling of titanium alloy, especially for thin-walled structural workpiece, is one of the main restrictions to the quality and efficiency of aeronautical manufacture. In the machining of titanium alloy, quite low cutting speed is always adopted for ensuring the tool life. Stability limits predicted by regular model ignoring process damping are much lower than actual limits, which may lead to terrible machining efficiency. In the paper, one milling dynamic model for thin-walled workpiece considering process damping is presented to predict stability limit. The computations and experiments indicate that the nonlinear model could provide accurate results. Besides the antivibration clearance angle designed could increase process damping to suppress chatter and improve machining surface quality effectively. Furthermore, the antivibration angle can expand speed range of process damping effects significantly.

However, it must be pointed out that the calculation model of process damping proposed in paper is a simplification of a much complicated interaction between the cutting edge, the flank face, and the workpiece. The interaction is highly dependent on the edge condition and in particular on tool wear. In the current work, only sharp cutters were utilized.

In summary, although lots of simplifications have been adopted in computational model, the importance and effect of model can be also shown in paper. In future work, more complex tool geometry will be tried out, and the effect of honed radius and flank wear will be investigated. 


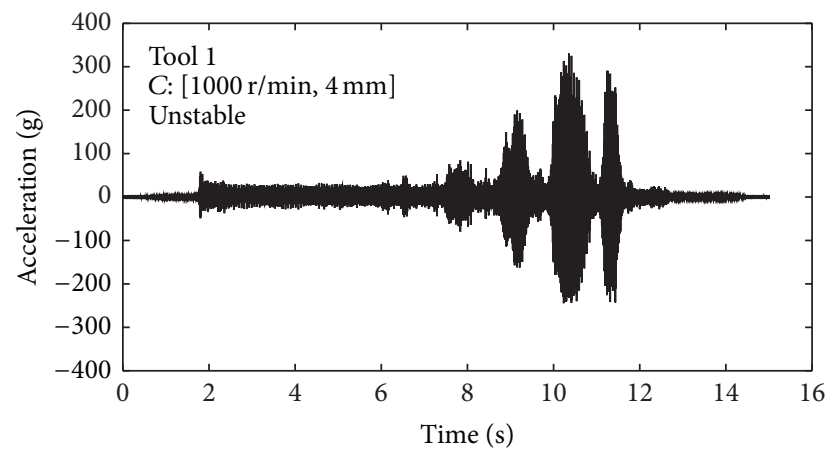

(a)

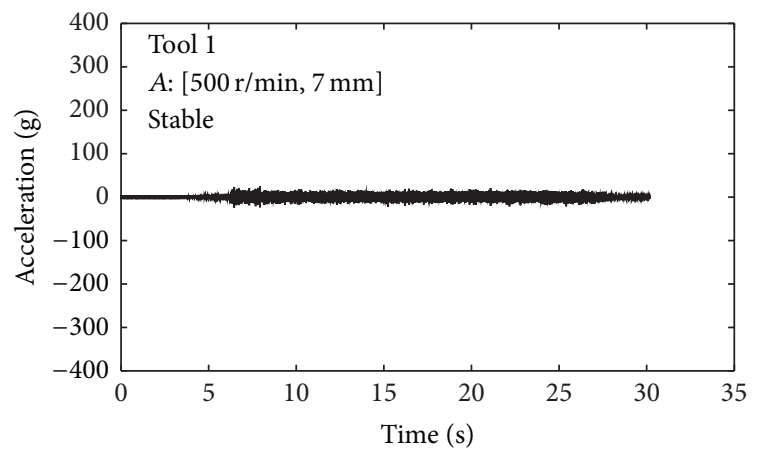

(b)

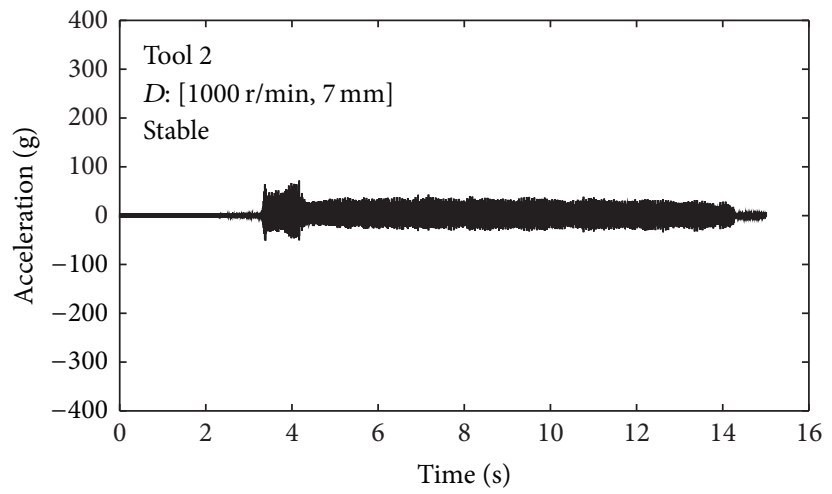

(c)

FIGURE 11: Spectral analysis results (tool 1).

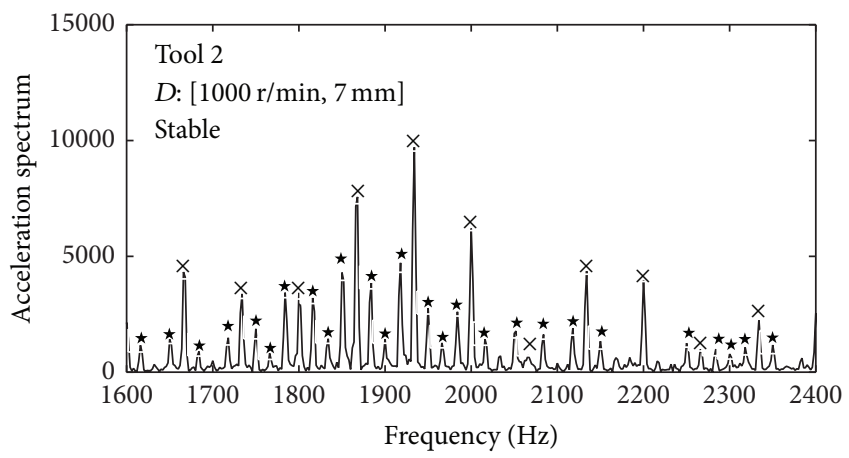

(a)

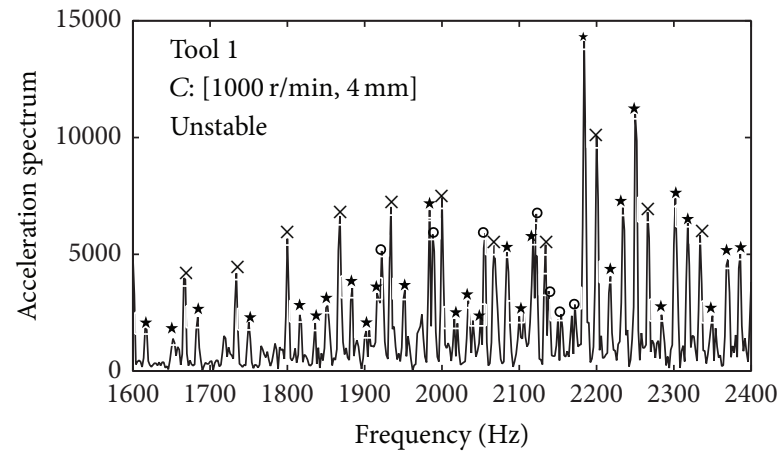

(b)

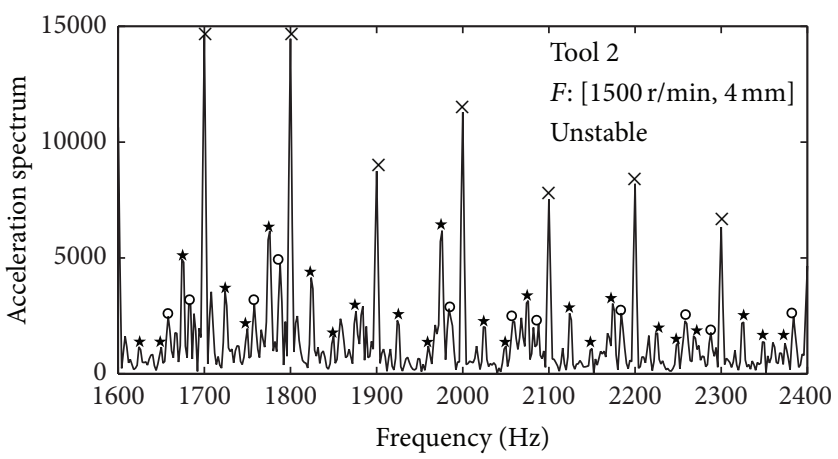

(c)

FIGURE 12: Spectral analysis results (tool 2). 


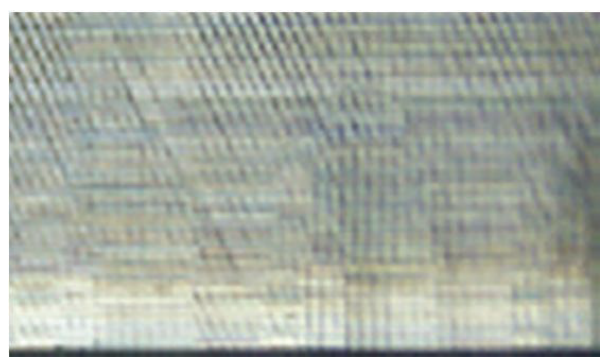

(a) Tool 1

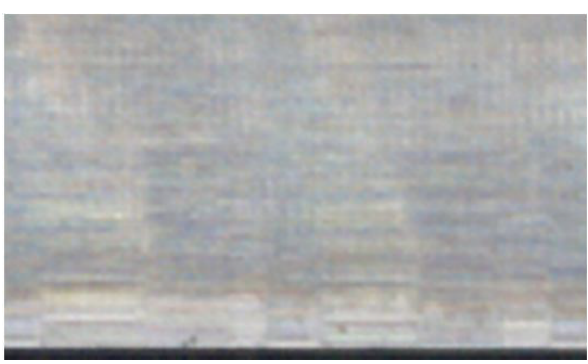

(b) Tool 2

FIgURE 13: The comparisons of surface quality.

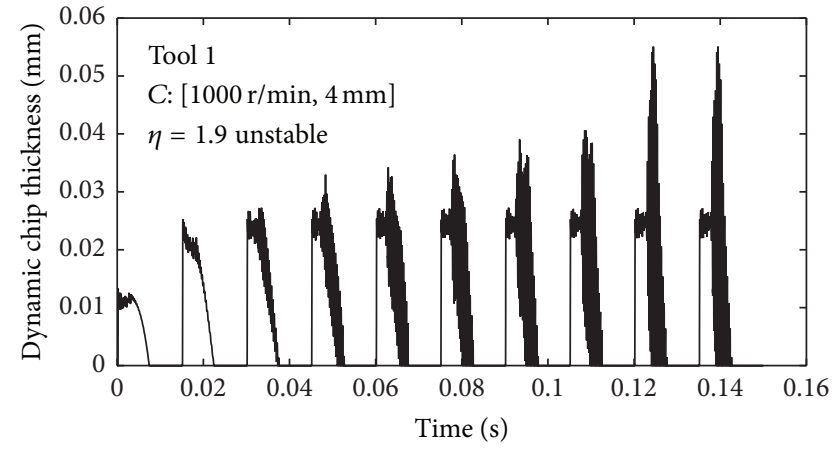

(a)

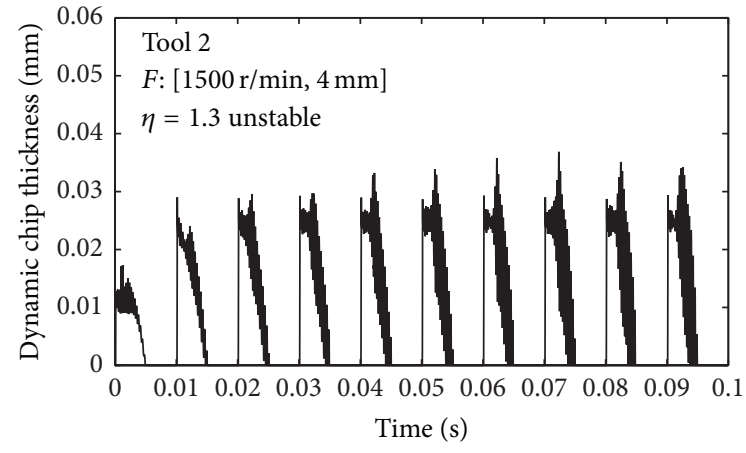

(b)

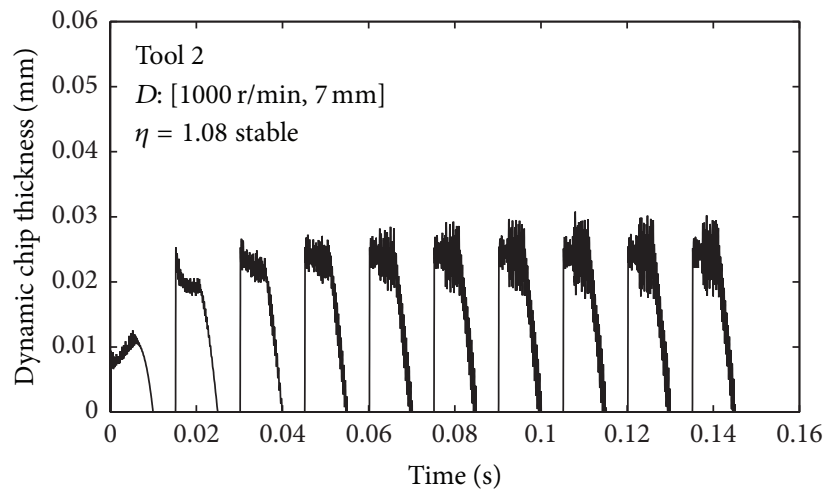

(c)

FIGURE 14: The dynamic chip thickness in different conditions.

\section{Appendix}

\section{A. The Calculation of $h$ in (6) and $u_{r, i}^{\text {wave }}$ in (2)}

We adsorbed some ideas in [23] and provide one useful method to calculate dynamic chip thickness $h$ and indentation area in milling of thin-walled workpiece. It considers the nonlinear effects of engagement and disengagement from the workpiece and could describe the surface wave caused by vibration of workpiece accurately.

A.1. Determined Function g. As shown in Figure 15, the tool is assumed to be rotating anticlockwise, the workpiece

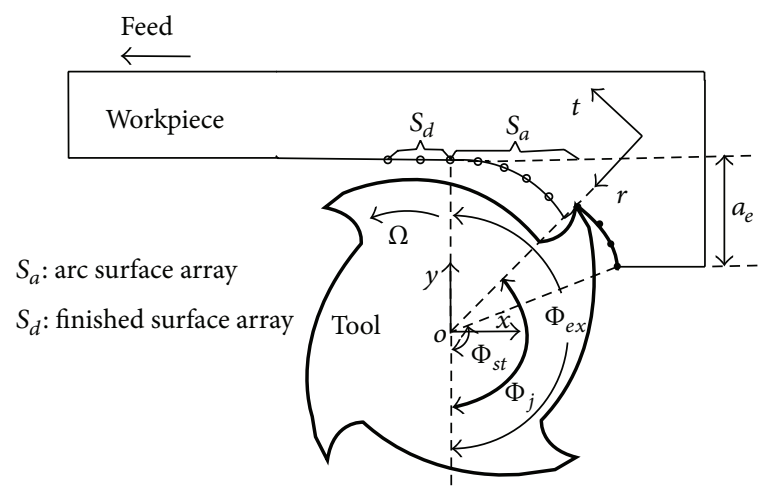

FIGURE 15: Milling kinematics model. 
surface is updated as material is removed, and the chip thickness is evaluated at each discretized point on the cutting edge. For downmilling, the workpiece surface is divided into two regions: the cutting arc surface and finished surfaces, represented by arrays of $(X, Y)$ coordinates, $S_{a}, S_{d}$, as shown in Figure 15. Here, $\Phi_{s t}$ is the entry angle, $\Phi_{e x}$ is the exit angle, and $a_{e}$ is radial cutting depth, for downmilling:

$$
\begin{aligned}
& \Phi_{s t}=\operatorname{arcos}\left(\frac{a_{e}-R}{R}\right), \\
& \Phi_{e x}=\pi .
\end{aligned}
$$

When angular position $\Phi_{j}<\Phi_{s t}$, the tool is out of contact with workpiece, and the cutting force and process damping force are zero. According to common analytic methods, when $\Phi_{j}>\Phi_{e x}$, the cutting force is also regarded as zero [4]. The unit step function which determines whether the tooth is in or out of the cutting, $g$ (mentioned in Section 3.1), is always defined as 1 when $\Phi_{j} \in\left(\Phi_{s t}, \Phi_{e x}\right)$; otherwise $g$ is 0 . However, in practice, the finished surface $S_{d}$ is affected probably by a tooth at the instant it passes through $\Phi_{j}=\pi$. Therefore, the scope of $g$ should be expanded. In the paper, the definition of $g$ is

$$
\begin{aligned}
& g=1 \quad \Phi_{s t}<\theta<\Phi_{e x}+\frac{a_{p}}{R} \tan (\beta), \\
& g=0 \quad \theta<\Phi_{s t} \text { or } \theta>\Phi_{e x}+\frac{a_{p}}{R} \tan (\beta),
\end{aligned}
$$

where $\theta$ is the angular position of tooth bottom (axial level $z=0$ ), which is shown in (5), and $a_{p}$ is axial cutting depth. When $\theta \in\left(\Phi_{s t}, \Phi_{e x}+a_{p} \tan (\beta) / R\right)$, the calculation of cutting force and process damping force at every axial level $z$ should continue.

Additionally, we should mention that the calculation of indentation area should also stop when corresponding angular position at $i$ th time point, $\Phi_{i}$, is smaller than entry angle $\Phi_{s t}$.

A.2. Calculation of Instantaneous Chip Thickness $h$. As mentioned in Section 3.1, the calculation of instantaneous chip thickness $h$ is of great importance in the whole computation process, which is required to describe the wave in workpiece surface accurately. As shown in Figure 16, two surface arrays are stored, one of the surface left by the previous tooth and one being created by the current tooth. Figure 16 shows how the surface is updated. At each time interval, a new point $\left(x_{i}, y_{i}\right)$ is added to the current surface at the angular position of the tooth, $\Phi_{i}$. If the tooth is cutting, the instantaneous position of tooth edge and vibration displacement of workpiece are used; otherwise a point is found on the previous surface at the tooth angle.

We provide one method to represent the wave in workpiece surface. As shown in Figure 16, this method generates a point on the surface at each time interval corresponding to the instantaneous position of the cutting edge and vibration displacement of workpiece.

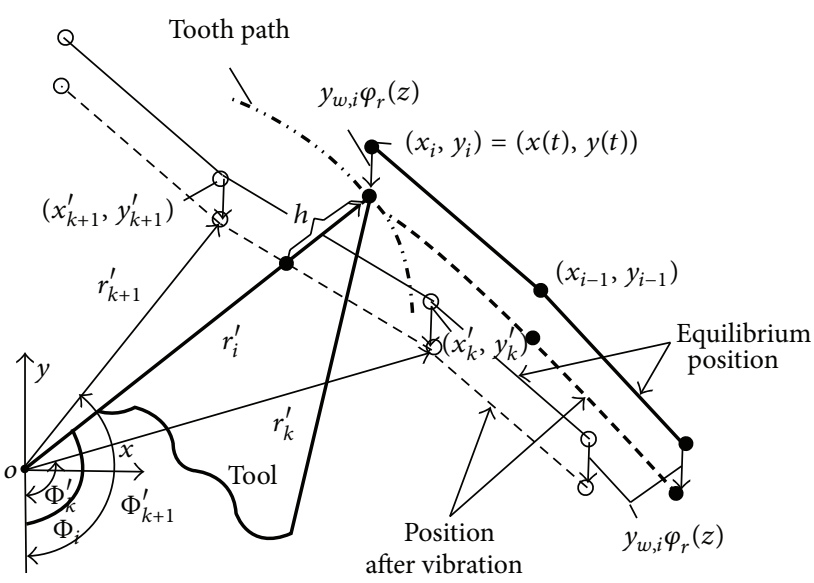

(a) Tooth submersed in workpiece

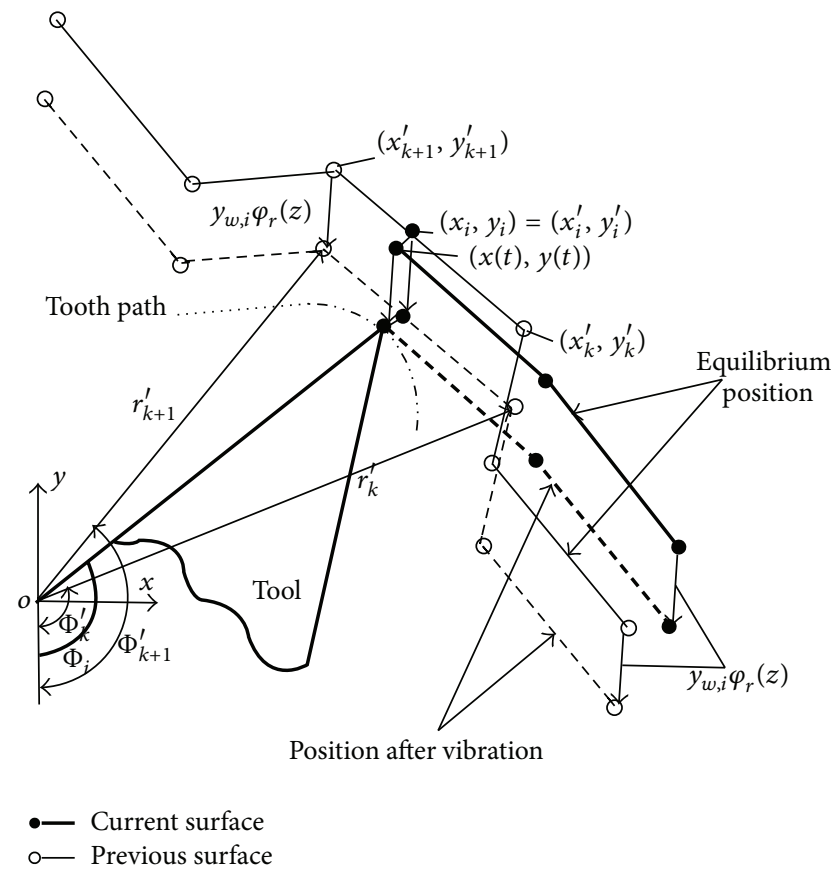

(b) Tooth separated from workpiece

FIGURE 16: The geometrical relationship between tool and workpiece.

In order to determine if the tooth is submersed in the workpiece, the intersection point of the tooth and the previous surface is calculated. The point on the previous surface, $\left(x_{k}^{\prime}, y_{k}^{\prime}\right)$, is found which has an angular position, $\Phi_{k}^{\prime}$, immediately preceding the angular position of the tooth, $\Phi_{i}$; the intersection point $\left(x_{i}^{\prime}, y_{i}^{\prime}\right)$ is then found by linear interpolation.

At angular position, $\Phi_{i}$, the coordinate values of cutting point on workpiece surface are

$$
\begin{aligned}
& x(t)=R \sin \left(\Phi_{i}\right), \\
& y(t)=-R \cos \left(\Phi_{i}\right)-y_{w, i} \varphi_{r}(z) .
\end{aligned}
$$


Firstly, the radial distance, $r_{i}^{\prime}$, is obtained by linear interpolation of the radial distance between points $k$ and $k+1$ on the previous surface:

$$
r_{i}^{\prime}=r_{k}^{\prime}+\frac{r_{k+1}^{\prime}-r_{k}^{\prime}}{\Phi_{k+1}^{\prime}-\Phi_{k}^{\prime}}\left(\Phi_{i}-\Phi_{k}^{\prime}\right)
$$

The coordinate values of intersection point $\left(x_{i}^{\prime}, y_{i}^{\prime}\right)$ are

$$
\begin{aligned}
& x_{i}^{\prime}=r_{i}^{\prime} \sin \left(\Phi_{i}\right), \\
& y_{i}^{\prime}=-r_{i}^{\prime} \cos \left(\Phi_{i}\right)-y_{w, i} \varphi_{r}(z) .
\end{aligned}
$$

As shown in Figure 16(a), it indicates that the tool is cutting workpiece if $R>r_{i}^{\prime}$; otherwise, it indicates the tool has separated from workpiece as shown in Figure 16(b). Thus, the dynamic chip thickness $h$ can be obtained:

$$
\begin{aligned}
& h=R-r_{i}^{\prime} \quad R>r_{i}^{\prime}, \\
& h=0 \quad R<r_{i}^{\prime} .
\end{aligned}
$$

Then the coordinate values of surface wave caused by current tooth path can also be generated. If the tooth is cutting workpiece, the coordinate values of surface wave, $\left(x_{i}, y_{i}\right)$, are taken as the current coordinate values of cutting point, $(x(t), y(t))$. Otherwise, the coordinate value of wave $\left(x_{i}, y_{i}\right)$ is taken as the value of $\left(x_{i}^{\prime}, y_{i}^{\prime}\right)$ :

$$
\begin{aligned}
& \left(x_{i}, y_{i}\right)=(x(t), y(t)) \quad h>0, \\
& \left(x_{i}, y_{i}\right)=\left(x_{i}^{\prime}, y_{i}^{\prime}\right) \quad h=0 .
\end{aligned}
$$

A.3. Calculation of Coordinates of Surface Wave in Radial Direction $u_{r, i}^{\text {wave }}$. For calculating indentation area and process damping force in accordance with (2)-(4), the radial coordinate values of surface wave, $u_{r, i}^{\text {wave }}$, should be also obtained. If tool is cutting workpiece, $u_{r, i}^{\text {wave }}$ is equal to the radial vibration displacement of workpiece, which can be obtained using $y_{w, i}$ and angular position $\Phi_{i}$, so does the corresponding radial vibration speed. Otherwise, if tool has separated from workpiece, $u_{r, i}^{\text {wave }}$ is taken as the ones caused by the previous tooth pass, which is also generated by linear interpolation. In (A.8), $u_{r, k}^{\text {wave, } 0}$ is radial coordinate values of wave caused by previous pass:

$$
\begin{array}{r}
u_{r, i}^{\text {wave }}=-y_{w, i} \varphi_{r}(z) \cos \left(\Phi_{i}\right), \quad \dot{u}_{r, i}^{\text {wave }}=-\dot{y}_{w, i} \varphi_{r}(z) \cos \left(\Phi_{i}\right), \\
h>0,
\end{array}
$$$$
u_{r, i}^{\mathrm{wave}}=u_{r, k}^{\mathrm{wave}, 0}+\frac{u_{r, k+1}^{\mathrm{wave}, 0}-u_{r, k}^{\mathrm{wave}, 0}}{\Phi_{k+1}^{\prime}-\Phi_{k}^{\prime}}\left(\Phi_{i}-\Phi_{k}^{\prime}\right), \quad \dot{u}_{r, i}^{\mathrm{wave}}=0
$$$$
h=0 .
$$

A.4. Feeding the Workpiece. The workpiece is fed into the tool at the rate $f_{z}[\mathrm{~mm} /$ tooth]. With a spindle speed, $n$, a time

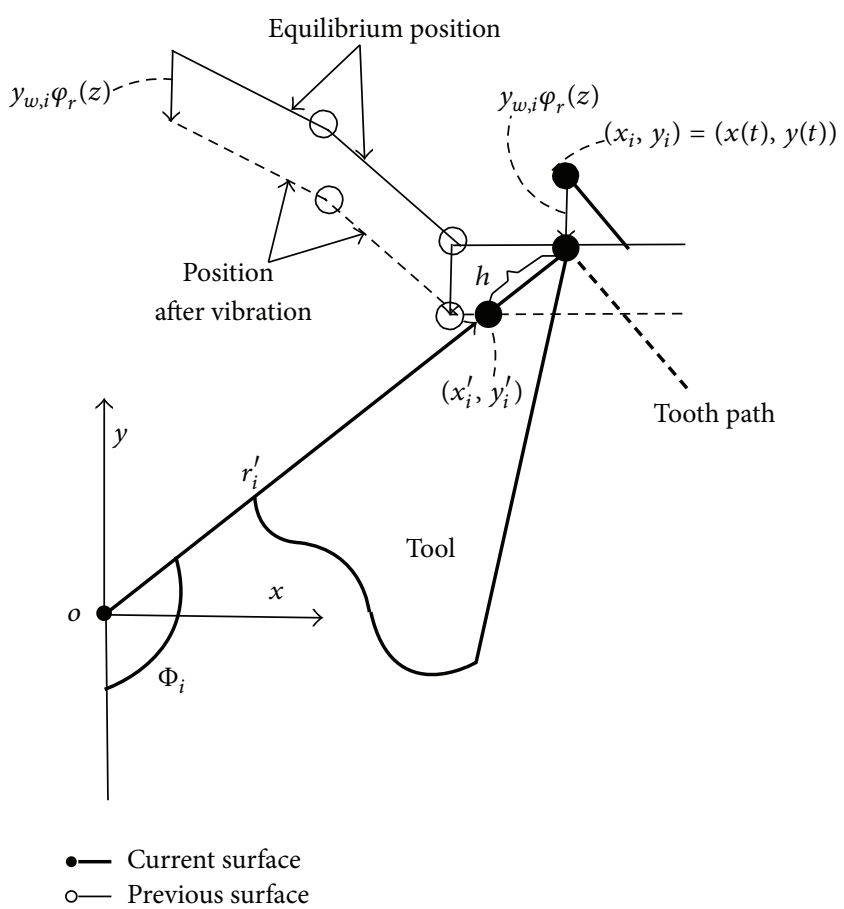

FIGURE 17: The geometrical relationship between tool and workpiece when tooth entering surface.

interval of $\Delta t$, and $N$ number of teeth, the motion of the workpiece along the $X$-axis during a single time step is

$$
\Delta x=-f_{z} \frac{N n}{60} \Delta t .
$$

The $X$ components of all points in all surface arrays are incremented by $\Delta x$ at each time step before the surface is updated due to the teeth cutting. Correspondingly, $u_{r, i}^{\text {wave }}$ and $u_{r, k}^{\text {wave }, 0}$ in (A.8) are also incremented by $-\Delta x \sin \left(\Phi_{i}\right)$.

A.5. Special Case. When tooth is just entering the arc surface as shown in Figure 17, tooth may first strike the upper uncut workpiece surface before cutting the surface cut by previous teeth. The chip thickness is found using (A.6) with the point $\left(x_{i}^{\prime}, y_{i}^{\prime}\right)$ found as intersection between the tooth edge and the line $\left(y=R \cos \left(\pi-\Phi_{s t}\right)+y_{w, i} \varphi_{r}(z)\right)$ as shown in (A.10). Then chip thickness $h$ is obtained using the above methods:

$$
\begin{aligned}
& x_{i}^{\prime}=-\left(R \cos \left(\pi-\Phi_{s t}\right)+y_{w, i} \varphi_{r}(z)\right) \tan \left(\Phi_{i}\right), \\
& y_{i}^{\prime}=R \cos \left(\pi-\Phi_{s t}\right)+y_{w, i} \varphi_{r}(z) .
\end{aligned}
$$

\section{Conflict of Interests}

The authors declare that there is no conflict of interests regarding the publication of this paper.

\section{Acknowledgment}

The research is sponsored by the National Natural Science Funds (51475234). 


\section{References}

[1] J. Tlusty and F. Ismail, "Special aspects of chatter in milling," Journal of Vibration, Acoustics, Stress, and Reliability in Design, vol. 105, no. 1, pp. 24-32, 1983.

[2] Y. Altintas and M. Weck, "Chatter stability of metal cutting and grinding," CIRP Annals: Manufacturing Technology, vol. 53, no. 2, pp. 619-642, 2004.

[3] Y. Altintas, Manufacturing Automation: Metal Cutting Mechanics, Machine Tool Vibrations, and CNC Design, Cambridge University Press, London, UK, 2nd edition, 2011.

[4] Y. Altintas, G. Stepan, D. Merdol, and Z. Dombovari, "Chatter stability of milling in frequency and discrete time domain," CIRP Journal of Manufacturing Science and Technology, vol. 1, no. 1, pp. 35-44, 2008.

[5] M. K. Das and S. A. Tobias, "The relation between the static and the dynamic cutting of metals," International Journal of Machine Tool Design and Research, vol. 7, no. 2, pp. 63-89, 1967.

[6] J. Tlusty, "Analysis of the state of research in cutting dynamics," Annals of the CIRP, vol. 27, no. 2, pp. 583-589, 1978.

[7] T. R. Sisson and R. L. Kegg, "An explanation of low-speed chatter effects," ASME Journal of Engineering for Industry, vol. 91, no. 4, pp. 951-958, 1969.

[8] D. W. Wu, "A new approach of formulating the transfer function for dynamic cutting process," Journal of Engineering for Industry, vol. 111, no. 1, pp. 37-47, 1989.

[9] B. Y. Lee, Y. S. Tarng, and S. C. Ma, "Modeling of the process damping force in chatter vibration," International Journal of Machine Tools and Manufacture, vol. 35, no. 7, pp. 951-962, 1995.

[10] A. M. Shawky and M. A. Elbestawi, "An enhanced dynamic model in turning including the effect of ploughing forces," Journal of Manufacturing Science and Engineering, Transactions of the ASME, vol. 119, no. 1, pp. 10-20, 1997.

[11] Y. Altintas, M. Eynian, and H. Onozuka, "Identification of dynamic cutting force coefficients and chatter stability with process damping," CIRP Annals-Manufacturing Technology, vol. 57, no. 1, pp. 371-374, 2008.

[12] C. Y. Huang and J.-J. Junz Wang, "Mechanistic modeling of process damping in peripheral milling," Journal of Manufacturing Science and Engineering, vol. 129, no. 1, pp. 12-20, 2007.

[13] C. Y. Huang and J.-J. Junz Wang, "Effects of cutting conditions on dynamic cutting factor and process damping in milling," International Journal of Machine Tools and Manufacture, vol. 51, no. 4, pp. 320-330, 2011.

[14] E. Budak and L. T. Tunc, "A new method for identification and modeling of process damping in machining," Journal of Manufacturing Science and Engineering, Transactions of the ASME, vol. 131, no. 5, Article ID 051019, 2009.

[15] E. Budak and L. T. Tunc, "Identification and modeling of process damping in turning and milling using a new approach," CIRP Annals: Manufacturing Technology, vol. 59, no. 1, pp. 403-408, 2010.

[16] L. T. Tunç and E. Budak, "Effect of cutting conditions and tool geometry on process damping in machining," International Journal of Machine Tools and Manufacture, vol. 57, pp. 10-19, 2012.

[17] L. T. Tunc and E. Budak, "Identification and modeling of process damping in milling," CIRP Annals-Manufacturing Technology, vol. 135, no. 2, pp. 1-12, 2013.

[18] K. Ahmadi and F. Ismail, "Experimental investigation of process damping nonlinearity in machining chatter," International
Journal of Machine Tools and Manufacture, vol. 50, no. 11, pp. 1006-1014, 2010.

[19] K. Ahmadi and F. Ismail, "Stability lobes in milling including process damping and utilizing multi-frequency and semidiscretization methods," International Journal of Machine Tools and Manufacture, vol. 54-55, pp. 46-54, 2012.

[20] Q. Song, X. Ai, and W. Tang, "Prediction of simultaneous dynamic stability limit of time-variable parameters system in thin-walled workpiece high-speed milling processes," The International Journal of Advanced Manufacturing Technology, vol. 55, no. 9-12, pp. 883-889, 2011.

[21] M. Wang, L. Gao, and Y. Zheng, "Prediction of regenerative chatter in the high-speed vertical milling of thin-walled workpiece made of titanium alloy," The International Journal of Advanced Manufacturing Technology, vol. 72, no. 5-8, pp. 707716, 2014

[22] E. Budak, Y. Altintas, and E. J. A. Armarego, "Prediction of milling force coefficients from orthogonal cutting data," Journal of Manufacturing Science and Engineering, Transactions of the ASME, vol. 118, no. 2, pp. 216-224, 1996.

[23] M. L. Campomanes and Y. Altintas, "An improved time domain simulation for dynamic milling at small radial immersions," Journal of Manufacturing Science and Engineering, Transactions of the ASME, vol. 125, no. 3, pp. 416-422, 2003. 

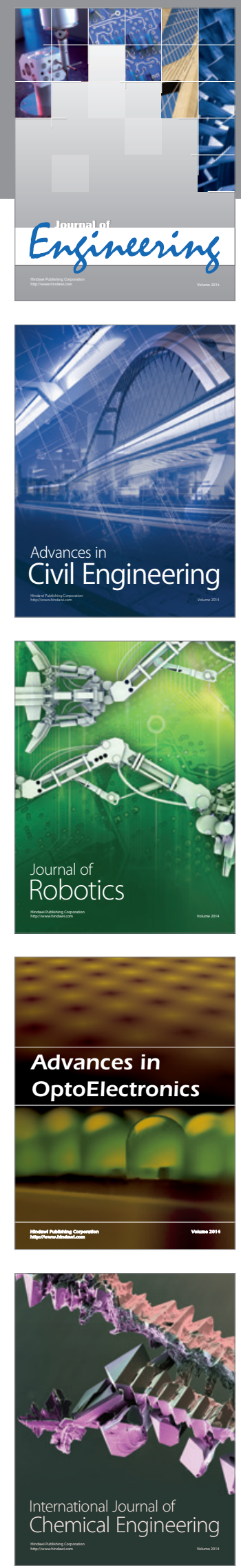

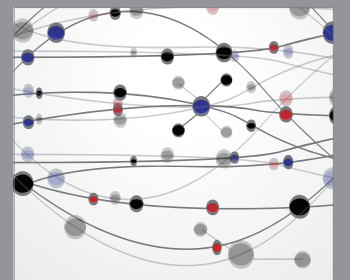

The Scientific World Journal
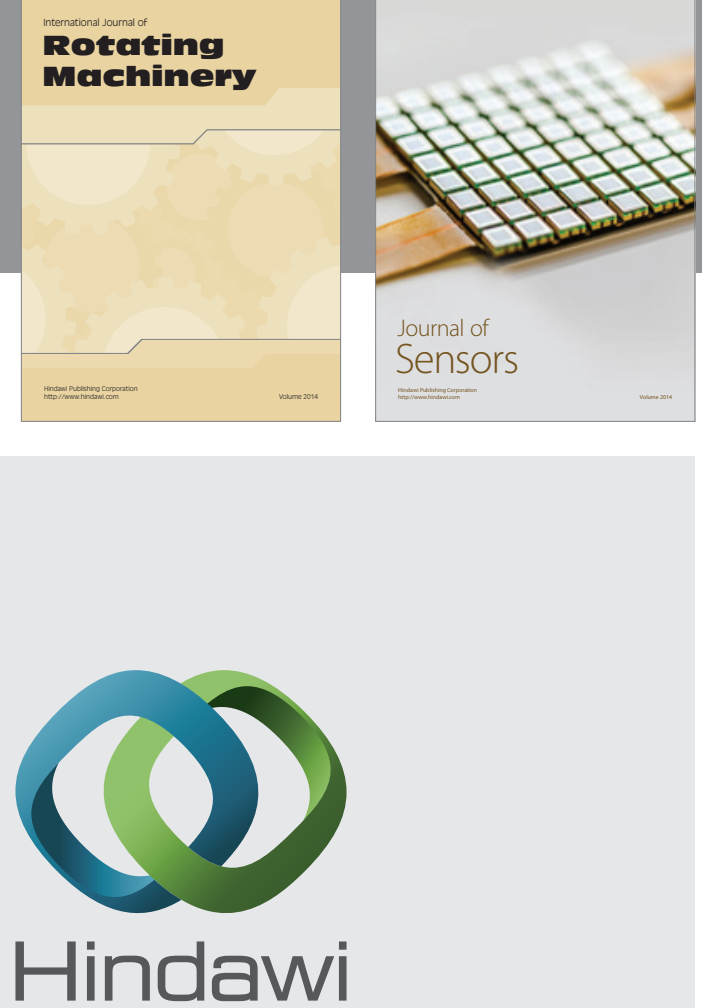

Submit your manuscripts at http://www.hindawi.com
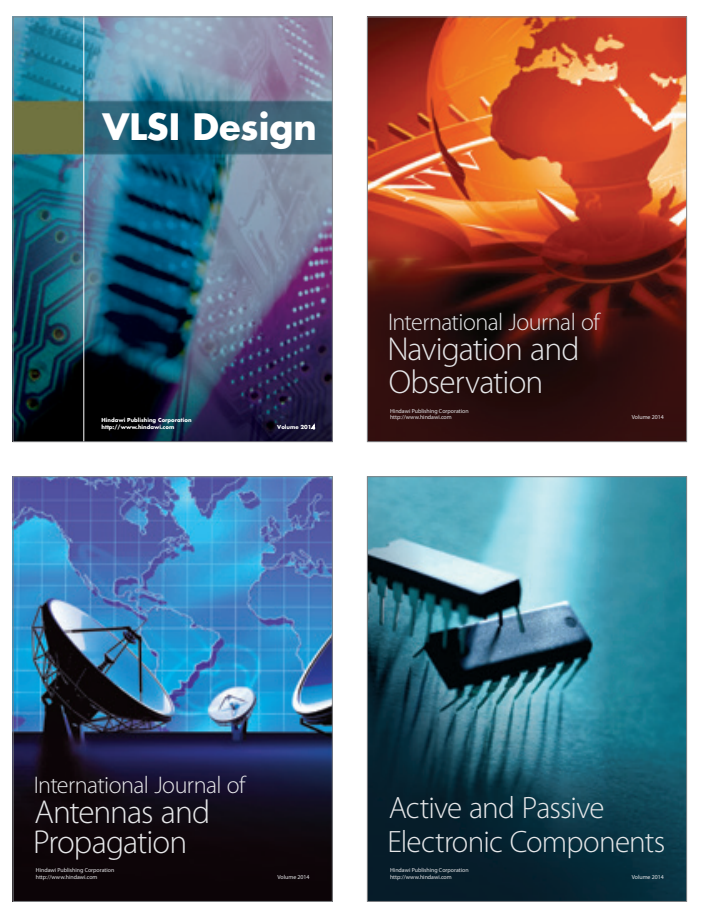
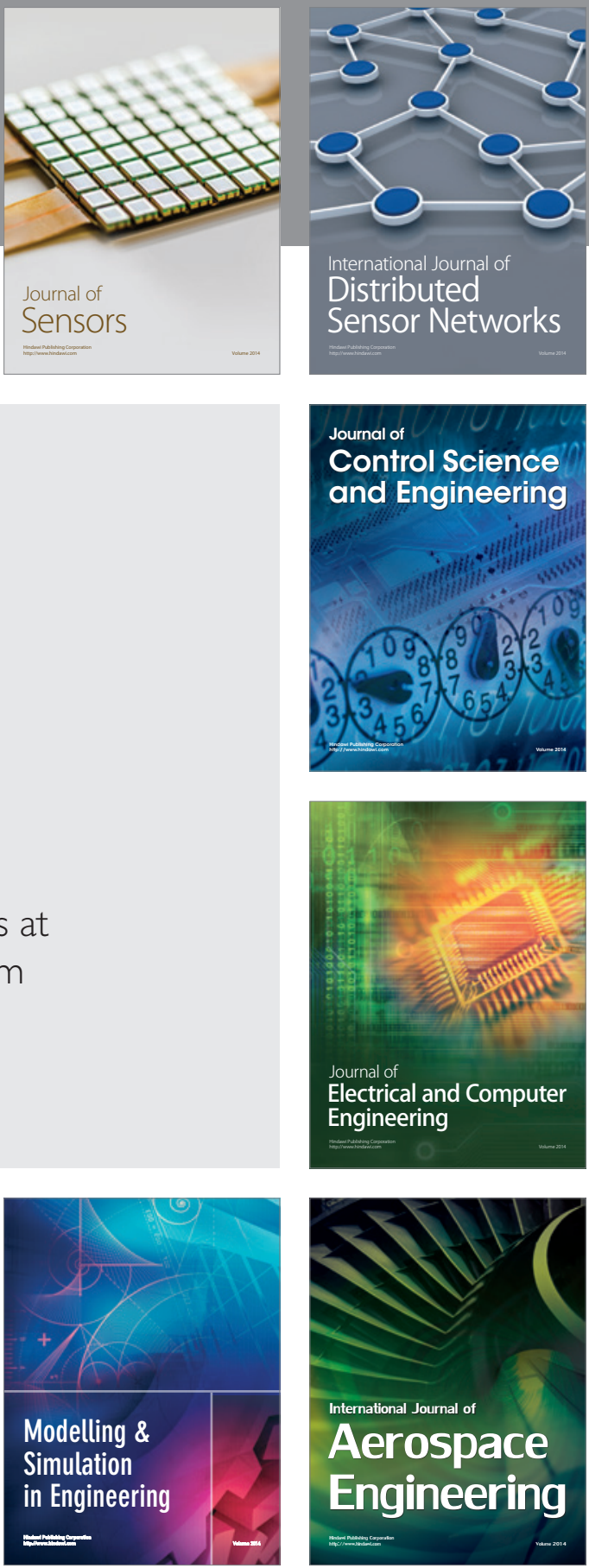

Journal of

Control Science

and Engineering
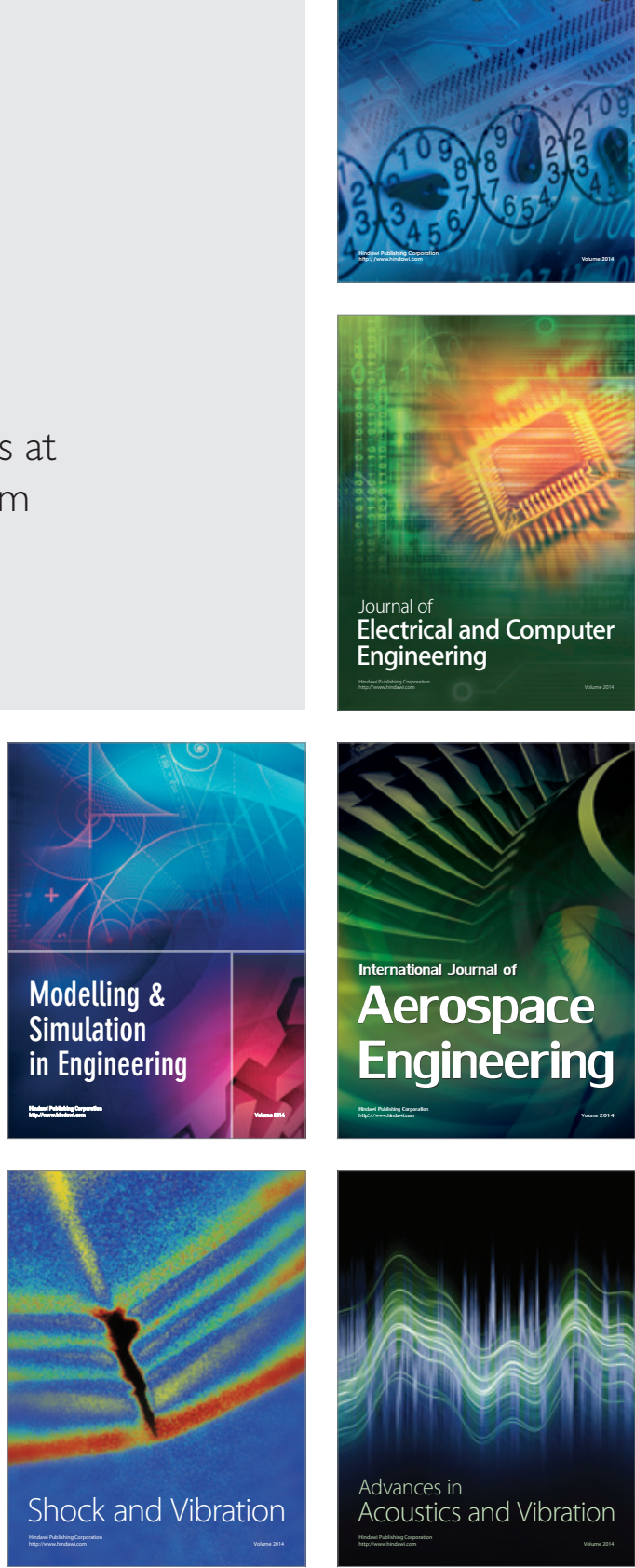